\title{
O BELO E O FEIO EM CENA E NOS BASTIDORES: DUAS MONTAGENS DE MACBETH NO BRASIL TURBULENTO DE 1992 ${ }^{1}$
}

\author{
Cristiane Busato Smith
}

Macbeth atravessa fronteiras, transbordando do palco para as ruas, do passado para uma estranha repetição na história e na cultura.

MARJORIE GARBER

Em 1985, o Brasil emergiu do regime militar de 21 anos otimista de que os novos líderes democráticos resolveriam os sérios problemas sociais e econômicos do país. No entanto, a fé no governo não tardou a esmorecer, já que o retorno à democracia demorou a se concretizar. Isso pôde ser comprovado sete anos depois, em 1992, com o escandaloso cenário político de corrupção desenfreada, inflação galopante e violência crescente que revoltou os brasileiros e culminou no impeachment do presidente Fernando Collor de Mello.

Não é, portanto, uma coincidência que duas montagens brasileiras de Macbeth (Macbeth, de Ulysses Cruz, e Trono de sangue, de Antunes Filho) tenham surgido no mesmo ano. Apesar de os temas de corrupção, poder, crueldade e violência presentes em Macbeth, de Shakespeare (1606), encontrarem ressonância com a realidade brasileira de 1992, os diretores escolheram linguagens estéticas distintas e tomaram muitas liberdades em relação ao texto de origem, desde suprimir e alterar cenas, bem como introduzir interpolações, de modo a atender às suas finalidades específicas. Mas quais são as consequências de tais interpolações? Como elas afetam/alteram/amplificam as predisposições políticas da peça? Mais importante ainda, até que ponto peças tão carregadas de interpretações políticas, como Macbeth, têm o potencial de tornar o público mais ativo e de transformá-lo em "espec-atores" — para usar um conceito desenvolvido por

\footnotetext{
${ }^{1}$ Trabalho apresentado no the 2013 Congress of the Latin American Studies Association (LASA), realizado de 20 de maio a 01 de junho de 2013 em Washington, DC. Título original: "Fair and Foul on and Behind the Scene: Two Macbeth Stage Productions in 1992 Turbulent Brazil". Tradução para o português de Thelma Christina Ribeiro Côrtes.
} 
SMITH - O belo e o feio em cena e nos bastidores...

Augusto Boal em Theatre of the Oppressed ${ }^{2}$ (1985) — em vez de meros espectadores? Será que somos capazes de entender e situar essas duas produções de Macbeth dentro do amplo cenário das manifestações públicas em prol do impeachment do presidente, ele mesmo uma espécie de Macbeth? Estas são algumas das questões que este trabalho irá discutir.

A vocação política de Macbeth está claramente estabelecida no texto, que aborda a ascensão e queda de um governante tirano, cuja ambição desenfreada traz destruição e desordem para a população. No que diz respeito ao tema, portanto, a peça oferece uma plataforma apropriada para se refletir sobre o Zeitgeist político de 1992, que vivenciou a ascensão e a queda de um presidente brasileiro que foi corrompido pelo poder e pela ganância. Essa obra também está permeada de história, na medida em que traz à cena o histórico rei Macbeth, tendo como fonte as Crônicas da Inglaterra, Escócia e Irlanda, de Hollinshed (500 anos antes de Shakespeare) ${ }^{3}$, e ao mesmo tempo lida explicitamente com referências contemporâneas de Shakespeare, particularmente a Conspiração da Pólvora (1605). Além disso, através dessa tragédia Shakespeare também prestou uma homenagem pessoal ao rei Jaime I, especialmente no que diz respeito ao seu estudo do sobrenatural, um assunto com o qual o rei $^{4}$ - que era o patrono da companhia de teatro do autor — estava profundamente envolvido. Ainda assim, a história de Macbeth estranhamente transcende o texto: ela permeia a história de suas montagens, de mais de 400 anos, e os acontecimentos políticos aos quais é associada. Como afirma Marjorie Garber, "a peça parece estar sempre em cena ou nos bastidores"5 (2008, p. 95). No Brasil, Macbeth esteve tanto nos bastidores que é justo perguntar se não esteve em cena também.

\footnotetext{
${ }^{2}$ N.T. A obra Teatro do Oprimido, de Boal, publicada originalmente em português, teve sua primeira edição em inglês em 1979.

${ }^{3}$ Veja Kenneth Muir. Macbeth. London: Methuen Drama, 1984, p. 164-181.

${ }^{4} \mathrm{O}$ rei Jaime I (1566-1625) foi um grande admirador das artes e patrono da companhia de teatro de Shakespeare, The King's Men.

${ }^{5}$ N.T. As traduções para o português de citações extraídas de edições de obras em língua inglesa são de responsabilidade da tradutora deste artigo, à exceção dos fragmentos de peças, quando foram usadas as traduções de Barbara Heliodora (SHAKESPEARE, William. Macbeth. Trad. Barbara Heliodora. Ed. especial. Rio de Janeiro: Nova Fronteira, 2011).
} 
SMITH - O belo e o feio em cena e nos bastidores...

Para Augusto Boal (1931-2009), teórico, diretor e dramaturgo brasileiro, que fundou o Teatro do Oprimido, o teatro é um campo de treinamento para a ação (1985, p. 40). Em virtude de ocorrer em um espaço público, ao vivo, o teatro não só detém o poder de refletir a realidade mas também de afetá-la (p. 39). As circunstâncias políticas do ano de 1992 exigiam tanto um teatro como um público politizados, público esse que Boal caracterizaria como formado por "espec-atores", que de forma deliberada e consciente transitam entre o mundo dos palcos e a realidade. Depois de anos de apatia, foi em 1992 que muitos brasileiros decidiram "adentrar" o drama e tornar-se "espec-atores".

Durante a severa ditadura, o teatro brasileiro recebeu contínuos golpes da censura e de uma economia flutuante ${ }^{7}$. O teatro estava sob vigilância permanente e, dentre outras medidas tomadas pela censura, cenas eram cortadas, estreias canceladas, montagens proibidas e atores presos. Apesar de toda a repressão, diversas produções vibrantes e ousadas da época atestam a força e a resistência do teatro. No regime pós-militar, durante as décadas de 1980 e 1990, o teatro teve de se adaptar a uma realidade e a temas diferentes. Alguns historiadores teatrais denominam esse período de crise e sugerem que, após a repressão, o teatro brasileiro havia perdido a sua urgência política. Em todo caso, é verdade que o teatro agora tinha de encontrar novas causas para alimentar sua arte. $\mathrm{O}$ retorno a textos clássicos, tais como Macbeth, de Shakespeare, foi um dos caminhos que os diretores teatrais escolheram para lidar com a nova realidade. Essa mudança apontava para novas e emocionantes direções para o teatro brasileiro, que neste momento via a possibilidade de fazer um investimento ao mesmo tempo estético e político na adaptação de textos clássicos. Com suas montagens do Macbeth shakespeariano os diretores Ulysses Cruz e Antunes Filho prestaram grandes contribuições para essa expansão artística.

\footnotetext{
${ }^{6}$ Nas palavras de Boal, o espectador ativo "assume o papel de protagonista, modifica a ação dramática, experimenta novas soluções, fala sobre planos para mudanças - em suma, treina-se para a ação de verdade". (BOAL, 1985, p. 122)

${ }^{7}$ Note-se que o $400^{\circ}$ aniversário de Shakespeare foi celebrado com centenas de eventos apoiados pelo governo, dentre os quais diferentes encenações de suas peças em todo o Brasil. (Veja Rauen, Margarida. Brasil. In: DOBSON, Michael; WELLS, Stanley. The Oxford Companion to Shakespeare. Oxford: Oxford University Press, 2002, p. 54).
} 
SMITH - O belo e o feio em cena e nos bastidores...

\section{O Macbeth de Ulysses Cruz}

A Escócia continua a mesma?

Ai, ai,

Quase com medo de se conhecer.

Macbeth 4.3

Descrita como "uma reflexão perturbadora sobre o poder" (Guzik, $1992^{8}$ apud Aguero, 2009, p. 107), a produção teatral brasileira de Macbeth (1992) percorreu várias cidades do país e tornou-se um sucesso comercial, apesar de ter sido recebida com críticas desfavoráveis. Parte de seu sucesso pode ser atribuído ao elenco, composto por estrelas da TV aberta, como Antonio Fagundes, Vera Fischer e Stênio Garcia. Para interpretar Macbeth, Fagundes - também produtor da peça - raspou a cabeça para que, desse modo, o público não o identificasse com o papel que havia desempenhado recentemente na $\mathrm{TV}^{9}: \mathrm{o}$ Macbeth de Fagundes exigia esta distinção. Mas, certamente, as conotações políticas do texto shakespeariano encontraram uma ressonância especial no cenário sombrio do Brasil de 1992, e precisam ser situadas neste contexto. Por isso, uma das intenções da peça era inflamar a pressão popular, como as palavras de Fagundes no programa explicitam:

Nada de novo sob o sol: o poder absoluto corrompe de forma absoluta. Serão todos esses assassinatos uma figura de retórica? De certa forma, não estamos mortos todos nós, ao ver nossa cidadania jogada na sarjeta? Ou pela indiferença que nos faz nadar nesse esgoto a céu aberto em que a sociedade brasileira se transformou? Será uma figura de retórica o fato de que três crianças são assassinadas por dia? E a fome? O desemprego? As doenças? A corrupção? Nosso único console é que o poder muda de mãos aqui sem derramamento de sangue (pelo menos o sangue deles não é derramado). [...] Vivemos dias shakespearianos. Como em Shakespeare, o povo está praticamente ausente da nossa história, o poder para governar é decidido pelo golpe de uma adaga, pela tinta de uma caneta, determinado por um consenso entre as elites, talvez devido a forças ocultas. Como em Shakespeare, o povo

\footnotetext{
${ }^{8}$ GUZIK, Alberto. Macbeth Exagera no Supérfluo. Jornal da Tarde, 19 mar 1992, sem número de página.

${ }^{9}$ Os críticos Guzik e Gláucia Leal associaram o novo visual de Fagundes ao dos neo-nazistas (skinheads) ou ao de Lex Luthor, o vilão do Super-Homem. (Vilão Outra Vez. Jornal da Tarde, p. 21, 1992.)
} 
SMITH - O belo e o feio em cena e nos bastidores...

observa, impassível, o duelo dos titãs que se revezam no governo. Essas pessoas que estão sempre sofrendo, sempre cheias de esperança, sempre enganadas. [...] Na realidade, a Inglaterra não tinha, na época [quando a peça foi encenada para Jaime I], tantos problemas como temos hoje. Essa montagem de Macbeth tem um objetivo similar ao que Shakespeare alcançou: acordar o público. (apud Aguero, 2009, p. 100) ${ }^{10}$

Fagundes não só convida o público a estabelecer comparações entre a situação do Brasil e a trama de Macbeth, como também incita as pessoas a exercerem sua cidadania e a mudarem o jogo. Com essas intenções em mente, a adaptação brasileira de Macbeth demandava importantes alterações do drama de Shakespeare, embora o enredo tenha permanecido praticamente fiel à sua fonte. Embora Ulysses Cruz tivesse sido criticado por simplificar demasiadamente o enredo (Fernandes, 2011; Guzik apud Aguero, 2012, p. 55 e 107), a simplificação e a popularização dos textos de Shakespeare estavam no coração do projeto MilkShakespeare, ${ }^{11}$ que Cruz havia criado com Fagundes.

Apesar de não ser grandiosa, a montagem de Macbeth $^{12}$ dirigida por Cruz é cuidadosa, tendo ideias engenhosas que refletem a intenção de Fagundes de "despertar o público". Isso já se manifesta nos adereços, que foram habilmente transformados em poderosos significantes políticos. O melhor exemplo é o uso de um pano de lona simples e grande, que representa o rei e sua ambição, e de forma inequívoca situa a peça no Brasil. Esta, na verdade, se inicia com o pano, sob o qual seres irreconhecíveis se movem erraticamente. Momentos depois, ele é levantado do chão em cinco cantos diferentes, de modo a representar, simultaneamente, uma coroa e uma tenda, de onde as "bruxas" irão surgir. Em outra interpolação significativa, Macbeth arrogantemente coroa a si mesmo pegando o adereço que está sobre o pano que cobre o chão. Sua sensação de contentamento

\footnotetext{
${ }^{10}$ N.T. O texto original de Fagundes, publicado no programa da peça, não foi localizado, por isso a citação está retraduzida do inglês (na versão de Aguero para a sua tese de doutorado Strange Images of Death: Violence and the Uncanny in Five Productions of Macbeth) para o português.

${ }^{11}$ A ideia era ter um projeto que não só encenasse peças de Shakespeare, mas que também oferecesse exposições, leituras, workshops, etc. Em outras palavras, um verdadeiro "milk-shake", nos termos de Ulysses. (http://omundoeumpalco.zip.net/shakespearianos/ulyssescruz.pdf. Acessado em 15 jun 2013.)

${ }^{12} \mathrm{O}$ vídeo desta produção pode ser visto no Global Shakespeares Video \& Performance Archive, disponível em: http://globalshakespeares.mit.edu/macbeth-cruz-ulysses-1992.
} 
SMITH - O belo e o feio em cena e nos bastidores...

é curta, porém, como pode ser visto quando ele pega o pano e envolve-se nele: o pano agora é um manto real pesado com o qual ele se arrasta com dificuldade pelo palco. Este é apenas um dos primeiros sinais do que sua ambição o levaria a fazer. Em seu esforço com o pano, Macbeth desenha um mapa do Brasil com ele, enquanto declara: "Senhor! Governar assim não vale a pena!"13. Visivelmente, o pano cumpriu a sua função: ele nitidamente localizou a peça no Brasil, mostrou o surgimento de um tirano e insinuou sua queda.

Em mais uma atitude ousada, que também situa culturalmente a peça no país, as bruxas são substituídas por três rapazes de origem indígena, que usam tangas e têm motivos tribais pintados em seus corpos. A solução não foi bem vista pelos críticos, como exemplificam Jairo Arco e Flecha, que a caracteriza de "incompreensível" (apud Aguero, 2009, p. 106), e Nelson de Sá, que descreve as bruxas como "saci pererês" cujas cenas “fazem rir" (apud Fernandes, 2011, p.60). Declaradamente, o desaparecimento das bruxas elimina uma camada psicológica importante para o estudo que Shakespeare faz das diversas facetas do mal. As "irmãs estranhas são como uma manifestação obscura do inconsciente de Macbeth ou como entidades sobrenaturais que o levam a seus crimes hediondos. Entretanto, por mais atordoante ou revelador que isso possa parecer $^{14}$, os críticos não conseguiram perceber as ironias políticas da maior intervenção de Cruz, que pode ser discutida através de duas afirmações diferentes. Em primeiro lugar, as "bruxas" são interpretadas por rapazes indígenas ${ }^{15}$ que se comportam como incapazes de falar ou andar apropriadamente, em uma alusão inequívoca à passividade do povo brasileiro em face do cenário político. Uma implicação adicional é que, ao abrir mão de uma das duas

\footnotetext{
${ }^{13}$ Os trechos da produção de Cruz citados não são os usados no texto original do autor. Eles são traduções de versões para a língua inglesa - estas sim, elaboradas a partir do texto original - feitas pela autora deste trabalho.

${ }^{14}$ Em sua dissertação de mestrado Cena Teatral e Recepção Estética - o Olhar dos Críticos para os espetáculos Trono de Sangue (1992) e Macbeth (1992), Fernandes oferece uma análise aprofundada de como os críticos avaliaram as produções de Cruz e Antunes. Fernandes afirma que os críticos estavam preocupados com questões estéticas e, não, políticas.

${ }^{15}$ Garnero explica que os atores eram adolescentes da escola de samba Vai Vai (106). Ela insinua que há um "subtexto racial” (106), principalmente porque eles são "os únicos negros na produção", mas não fundamenta sua insinuação.
} 
SMITH - O belo e o feio em cena e nos bastidores...

principais influências sobre os crimes de Macbeth (sendo Lady Macbeth a segunda), a culpa recai quase que totalmente sobre ele, ou sobre ele e sua esposa ${ }^{16}$, acentuando, assim, a responsabilidade individual dele/deles, em vez de compartilhá-la com os poderes sobrenaturais.

Outra alteração é que Cruz confere ao porteiro (interpretado por Stênio Garcia) um papel ampliado: ele não só incorpora personagens diferentes, mas também funciona como uma espécie de coro, elucidando a trama e explicando os papéis de alguns personagens, por vezes orquestrando a ação. $\mathrm{O}$ discurso a seguir ocorre após o assassinato do rei Duncan e logo antes da coroação de Macbeth, e ilustra o processo de conflação pelo qual o texto de Shakespeare foi submetido bem como as múltiplas vozes que o porteiro brasileiro absorve do texto fonte. Inicialmente, Stênio Garcia incorpora e adapta as palavras do "velho", de Rosse e Macdfuff no ato 2, cena 4: “[gritando] Crime hediondo! Em setenta anos, eu já passei por tudo nessa vida. No entanto, uma noite foi o suficiente para transformar tudo o que vivi em nada. A escuridão cobre o dia, que se esconde de vergonha da fúria sangrenta da humanidade. (...) O quão contrários à natureza são esses assaltos. Malcolm, filho de Duncan, o assassino do próprio pai? Que ambição é essa que destrói a origem de sua própria vida?" 17 Imediatamente após esta fala, Garcia habilmente muda o tom e adota

\footnotetext{
${ }^{16}$ Se Lady Macbeth tem ocupado nas artes visuais o papel cultural da mulher perigosamente poderosa, desde o século XVIII, com retratos de atrizes, sua imagem nos séculos XX e XXI invade os noticiários em comparações caricaturadas com Margaret Thatcher, Hillary Clinton, Condoleeza Rice e Nancy Pelosi. Lady Macbeth não goza da mesma popularidade nos noticiários brasileiros, mas com certeza o público seria capaz de estabelecer semelhanças entre a poderosa e ambiciosa rainha e a mulher mais mal-afamada em 1992: Zélia Cardoso, ministra da Economia. Responsável pelo congelamento de $80 \%$ dos ativos financeiros do país sendo este, de longe, o choque mais brusco que o Brasil sofreu - durante os 14 meses em que ocupou o cargo de ministra, ao invés de combater a inflação, Cardoso avivou-a, deixando-a pronta para subir novamente. Chamada de "Dama de Ferro", em sua encarnação como tal, ela ocupa uma posição análoga à de Lady Macbeth: ambiciosa, traiçoeira, uma mulher sem escrúpulos. Embora ela tenha renunciado um ano antes, sua imagem ainda estava muito viva no imaginário popular brasileiro em 1992.

${ }^{17}$ Cruz dilui e reduz o texto mais denso de Shakespeare para poder ser incorporado pelo personagem do Porteiro (Stenio Garcia). O texto original:

Old Man. Threescore and ten I can remember well;/Within the volume of which I have seen/Hours dreadful, and things strange, but this sore night/Has trifled former knowings. (lines 1-4)

Rosse. [...] And yet dark night strangles the traveling lamp./Is't night's predominance, or the day's shame,/That darkness does the earth entomb,/When living light should kiss it? (lines 5-11)
} 
SMITH - O belo e o feio em cena e nos bastidores...

gestos diferentes, transformando-se no narrador: “Agora, estamos diante de um enterro e de uma coroação. Os destinos de dois homens estão cruzados. O corpo do rei Duncan é levado para sua terra natal e Macbeth é coroado. Alegria para uns. Tristeza para outros. Assim é a vida." Estas múltiplas vozes com diversas funções são habilmente executadas por Garcia e funcionam muito bem para esta encenação de Macbeth, uma peça não muito conhecida no Brasil, onde Shakespeare continua a ser um ícone da cultura de elite. Ao atuar como um mediador entre Macbeth e o público, a ideia é que o porteiro/Garcia seria capaz de fazer mais do que simplesmente explicar a história: ele iria despertar a consciência crítica do público e sua capacidade de ação evitando, ao mesmo tempo, empatia ou autoidentificação, em sintonia com as práticas teatrais tanto de Boal como de Brecht ${ }^{18}$. Este dispositivo teatral crítico, que promove um distanciamento da peça, é mais desenvolvido na produção de Antunes, que irei investigar a seguir.

\section{Trono de sangue, de Antunes Filho}

Será que o vasto oceano de Netuno

Pode lavar o sangue destas mãos?

Não; nunca! Antes estas mãos conseguiriam

Avermelhar a imensidão do mar

Tomando rubro o verde.

Macbeth, 2.2

$[\ldots]$

Macduff. [...] Malcolm, and Donalbain, the King's two sons,/Are stol'n away and fled; which puts upon them/Suspicion of the deed.

(lines 25-28)

Rosse. 'Gainst nature still/

Thriftless Ambition, that will ravin up/

Thine own life's means! (lines 28-30)

${ }^{18}$ Brecht e Boal têm posições muito semelhantes em relação ao perigo da empatia. De acordo com estes autores, a empatia desgasta a capacidade de pensamento crítico e de ação. A fim de obter o "distanciamento" necessário, o Teatro Épico de Brecht recorreu a uma variedade de mecanismos anti-ilusionistas, tais como música, luzes e projeções, dentre outros. No Teatro-Fórum de Boal, por outro lado, existe um certo grau de envolvimento, no sentido de que se espera que o "espec-ator" participe física e mentalmente. 
SMITH - O belo e o feio em cena e nos bastidores...

Trono de sangue (1992) reflete o mesmo cenário político a partir de uma perspectiva radicalmente diferente: o diretor Antunes Filho escolhe a célebre adaptação cinematográfica de Macbeth, Trono manchado de sangue (1957), do diretor japonês Kurosawa, e elementos do Teatro Nô para experimentar diferentes linguagens culturais e estéticas, a fim de adaptar Shakespeare. O resultado foi uma bela realização visual e estética, como foi observado por muitos críticos ${ }^{19}$. Todavia, se já havia sido difícil para os críticos identificarem as inclinações políticas da adaptação de Cruz, no caso de Antunes isto foi simplesmente ignorado ou apenas mencionado en passant, como se a estética pudesse simplesmente mascarar a política.

Um aspecto observado em diversas críticas foi o grau de violência e brutalidade de Trono de sangue. Isso reflete a escolha de Antunes de "mergulhar em um universo de violência" (apud Aguero, 2012, p. 108).

De fato, como o título anuncia, o sangue penetra assustadoramente nesta montagem de Macbeth: o piso do palco é pintado com um vermelho muito brilhante, uma alusão visual a "avermelhar a imensidão do mar" (2.2), fluido e sempre presente, tornando-se um fio condutor importante que ilustra as batalhas sangrentas que serão "vencidas ou perdidas". O palco despido e as paredes nuas caiadas de branco transmitem uma sensação perturbadora de reclusão e desamparo. Se a situação de violência nas prisões brasileiras já era sombria, assim como a estranha história das produções de $\operatorname{Macbeth}^{20}$, foi perturbador constatar que o piso ensanguentado de Trono de sangue se materializaria cinco meses depois, no Complexo Penitenciário do Carandiru, em São Paulo, onde a polícia matou 111 presos a tiros, e feriu 130, para conter um motim. O fato de a polícia não ter feito nenhum esforço para negociar

${ }^{19}$ Em seu texto "Text, Performance and Film: an Intermedial Reading of Antunes Filho's Throne of Blood/Macbeth", Mail Marques de Azevedo e Liana de Camargo Leão fazem uma avaliação estética de Trono de Sangue. O trabalho foi apresentado no World Shakespeare Congress, realizado em Praga, República Tcheca, em 2011.

${ }^{20}$ A história das produções de Macbeth tem sido envolta em superstições. De acordo com uma tradição teatral, pronunciar o nome Macbeth dentro de um teatro irá causar um desastre. Ainda hoje essa crença prevalece entre os atores, que encaram como amaldiçoada a história de má sorte que aconteceu com as montagens da peça. 
SMITH - O belo e o feio em cena e nos bastidores...

tornou o crime ainda mais chocante. Dada a magnitude e a brutalidade da violência, o massacre do Carandiru, como ficou popularmente conhecido, ${ }^{21}$ é considerado uma grave violação aos direitos humanos, uma das muitas "manchas malditas" que não podem ser lavadas das ensanguentadas mãos brasileiras.

Outra característica marcante de Trono de sangue é a representação das três bruxas, interpretadas por dois atores. Descendo do teto em um andaime, eles surgem como a encarnação das Parcas, as três deusas que iriam tecer o destino de Macbeth na roca de fiar. Sua aparição é realmente agourenta, eles se assemelham a fantasmas, vestidos com trapos brancos sobre seus corpos, e estão cercados por velas, como se estivessem prontos para realizar um ritual macabro. Tornando reais as palavras de Banquo, de que "[elas] parecem mulheres, / Mas [suas] barbas proíbem que [elas] afirmem que o são" (1.3), outro elemento desestabilizador neste cenário é que uma das bruxas é um manequim. Este é apenas um dos efeitos de distanciamento que podem ser atribuídos à prática teatral de Antunes em sua releitura de Macbeth. O manequim imóvel chama a atenção para a teatralidade da cena, bem como sinaliza a passividade do povo brasileiro, sendo o próprio uma marionete manipulada por um governo titereiro e corrupto. Além disso, a rotação da roca aponta para a inevitável passagem do tempo, os amanhãs e amanhãs, mas é também uma manifestação literal da velha frase "conjurar um feitiço", que significa amaldiçoar alguém, refletindo as lendas e superstições teatrais que cercam a "peça amaldiçoada".

Torna-se claro que Antunes, em sua montagem de Macbeth, não está preocupado em oferecer ao público uma ilusão de realismo. Em vez disso, os rostos esbranquiçados/pálidos confeccionados com grossas sobrancelhas pintadas copiam as

\footnotetext{
${ }^{21}$ É verdade que, mesmo antes do massacre do Carandiru, a violência já vinha crescendo no Brasil. Um exemplo disso são os casos de assassinatos de meninos de rua e os chamados sequestros-relâmpago. Muitas rebeliões vinham irrompendo em presídios com condições de vida desumanas, sendo respondidas com enorme violência. O massacre do Carandiru ocorreu na antiga Penitenciária do Carandiru, em São Paulo, uma das prisões mais populosas do mundo, com 7.000 detentos. O trágico incidente tornou-se o tema de muitas canções, inclusive da popular "Haiti", de Caetano Veloso e Gilberto Gil, e foi documentado no livro Estação Carandiru (1999), que também inspirou o filme com o mesmo título (2003).
} 
SMITH - O belo e o feio em cena e nos bastidores...

tradicionais máscaras Nô e trazem à tona a natureza ficcional do teatro. Da mesma forma, os personagens, caracterizados à moda Nô, se arrastam pelo palco, evocando desolação e desespero. Uma perturbada Lady Macbeth cambaleia vacilante com os ombros curvados, inclinando-se contra as paredes, como se sua ambição fosse um fardo pesado demais para suportar. Na verdade, Antunes presta igualmente uma homenagem a Shakespeare e a Kurosawa e, ao fazer isso, também convida o público a historicizar o drama de Macbeth. Afinal, a mesma trama de ambição desenfreada, corrupção, traição e violência que assalta Macbeth e que contamina a fictícia Escócia poderia muito bem acontecer na antiga Escócia do rei Macbeth, como Hollinshed narra, ou na trama para explodir o Parlamento durante o reinado de Jaime I da Inglaterra shakespeariana ${ }^{22}$, ou mesmo durante o Japão feudal. E estava, de fato, acontecendo no Brasil de hoje. Na verdade, na cena final, Antunes sutilmente lembra o público da contemporaneidade de Macbeth ao ter o corpo moribundo do protagonista arrastado pelo palco ao som de "Total Death", uma música da banda de metal Kreator, conhecida por suas letras violentas e politicamente motivadas. Enquanto o corpo de Macbeth resiste à morte, sacudindo-se e tendo convulsões no palco, "Total Death" clama em alto e bom som pela morte de "porcos de guerra políticos [que] só têm merda na cabeça" ${ }^{\text {"23 }}$. Como um potencial significante político, a música ajuda a trazer o enredo de Macbeth para o presente e descreve o último quadro narrativo. Assim, através do tratamento agudo de múltiplos quadros narrativos no Trono de sangue de Antunes, o público é convidado a não se identificar emocionalmente, e por isso é capaz de estabelecer uma distância estética da peça. Essa abordagem, parte brechtiana, parte

\footnotetext{
${ }^{22}$ A Conspiração da Pólvora (1605) foi um plano fracassado de um grupo de ingleses católicos, liderados por Robert Catesby, para explodir a Câmara dos Lordes e assassinar o rei Jaime I.

${ }^{23}$ A letra de "Total Death" (Kreator) traduzida: "Chegou a hora, a paz não consegue suportar / Os mestres da mudança agora governam a terra / Empurrem a mudança deles e mandem a morte / Políticos, porcos chauvinistas, só tem merda na cabeça / Tentem correr ou se escondam da morte / Vocês vão queimar e sangrar pela cabeça / Morte a tudo, Morte a todos / Ninguém pode escapar das chamas ardentes / A carne e a pele apodrecem nos seus rostos / Centenas de explosivos pairam sobre cada alma / Destruir o ser humano é o objetivo deles / Destruam as armas desta terra / Ou vai ser o fim do mundo / Se eles derem uma ordem a morte vai ganhar vida / E não vai haver Deus / Que nos ajude quando morrermos".

< http://www.lyricsmode.com/lyrics/k/kreator>. Acessada em 12 jun 2013.
} 
boaliana, funciona particularmente bem com tais dispositivos de enquadramento, já que o espectador é incitado a fazer comparações críticas entre eles, evitando-se a noção de uma narrativa autossuficiente e inviolável. Além disso, essa abordagem é didática, no sentido de que leva o espectador a não tomar o estilo e o conteúdo da narrativa como algo certo, e a adotar uma atitude de juízo crítico.

\section{Conclusão}

Num movimento circular, de volta à epígrafe deste trabalho, se "Macbeth atravessa fronteiras, transbordando do palco para as ruas", qual foi o desfecho das ruas brasileiras de 1992 e da trama do "Macbeth brasileiro"? Não houve justiça poética para esse drama. Diante da quase certeza da condenação e destituição de cargo pelo Senado, depois de uma investigação à la Watergate e de manifestações públicas maciças por seu impeachment, Fernando Collor de Mello renunciou no dia 29 de dezembro. No entanto, ao contrário da infalível derrocada do herói trágico, Collor teve seus direitos políticos restaurados e foi eleito senador, representando seu estado natal, Alagoas, desde 2006.

A história tem uma estranha tendência de se repetir, mas talvez isso seja particularmente verdadeiro no Brasil, onde as pessoas estão acostumadas a ver seus heróis se transformarem, do dia para noite, em vilões corruptos. Embora tenha havido avanços sociais e econômicos significativos no Brasil depois de 1992, a corrupção e a violência ainda estão "firmes e fortes".

Como explica Terry Eagleton,

[a] tarefa de um teatro não é refletir uma realidade fixa, mas demonstrar como personagens e ação são historicamente produzidos e, assim, mostrar como eles poderiam ter sido e ainda podem ser diferentes. A peça em si, portanto, torna-se um modelo desse processo de produção; ela é menos uma reflexão da realidade social do que uma reflexão sobre essa realidade." (apud Babbage, 2004, p.44) 
Não é como se o teatro fosse mudar a realidade, mas ele, na verdade, pode ter uma influência e, ocasionalmente, pode ser aquilo que faz pender a balança.

Para um país "quase com medo de se conhecer" (4.3.), como diz Rosse em Macbeth, um país que não se lembra de seu passado, e onde os mesmos erros são cometidos, disfarçados apenas por detalhes ligeiramente diferentes, já está mais do que na hora de haver outras produções viscerais de Macbeth como as dirigidas por Ulysses Cruz e Antunes Filho.

\section{Referências}

AGUERO, Dolores Aronovich. Strange Images of Death: Violence and the Uncanny in Five Productions of Macbeth. 2009. Tese (Doutorado) - Programa de PósGraduação em Letras/Inglês e Literatura Correspondente. Universidade Federal de Santa Catarina, Florianópolis, 2009.

BABBAGE, Frances. Augusto Boal. New York: Routledge, 2004.

BOAL, Augusto. Theatre of the Oppressed. Trans. Charles A. McBride; Maria-Odilia Leal McBride. New York: Theatre Communications Group, 1985

DOBSON, Michael; WELLS, Stanley. The Oxford Companion to Shakespeare. Oxford: Oxford University Press, 2002

FERNANDES, Renan. Cena teatral e recepção estética - o olhar dos críticos para os espetáculos Trono de sangue (1992) e Macbeth (1992). 2011. Dissertação (Mestrado) - Programa de Pós-Graduação em História Social. Universidade Federal de Uberlândia, Uberlândia, 2011.

GARBER, Marjorie. Shakespeare and Modern Culture. New York: Pantheon, 2008. MUIR, Kenneth. Macbeth. London: Methuen Drama, 1984. 